\title{
School Teachers' Knowledge about Epilepsy in Kathmandu Metropolitan City
}

\author{
Khanal K, ${ }^{1}$ Maharjan $\mathrm{R},{ }^{2}$ Pokharel BR, ${ }^{3}$ Sanjel $\mathrm{S}^{1}$
}

${ }^{1}$ Department of Community Medicine

${ }^{2}$ Department of Nursing

${ }^{3}$ Department of Internal Medicine

Kathmandu University School of Medical Sciences

Dhulikhel, Kavre, Nepal.

\section{Corresponding Author}

Kishor Khanal

Department of Community Medicine

Kathmandu University School of Medical Sciences

Dhulikhel, Kavre, Nepal.

E-mail: khanalkishorst@gmail.com

Citation

Khanal K, Maharjan R, Pokharel BR, Sanjel S.

School Teachers' Knowledge about Epilepsy in Kathmandu Metropolitan City. Kathmandu Univ Med J 2015;52(4):316-22.

\section{ABSTRACT}

\section{Background}

Studies on Knowledge towards epilepsy among school teachers are very limited on developing countries especially with reference to Nepal. Level of knowledge of schoolteachers plays an important role on providing a greater educational support for epileptic child and to maintain good communication skills between epileptic and normal child.

\section{Objective}

Objective of this study is to assess the level of knowledge about epilepsy and its associated factors among school teachers.

\section{Method}

A cross sectional study was conducted from $10^{\text {th }}$ June to $4^{\text {th }}$ July, 2014 among 165 teachers teaching in six different schools of Kathmandu Metropolitan City. A selfadministrated questionnaire consisting of structured and multiple choice questions were designed to collect information on the teacher's socio-demographic profile and knowledge about epilepsy. A scoring system was developed for each question: each correct answer was given a score of 1 , and a score of 0 for wrong answer. Total score was categorized on two categories: Good Knowledge and Poor Knowledge.

\section{Result}

Teacher's age did not correlate significantly with their knowledge about epilepsy but total years of teaching experiences and knowledge about epilepsy were found to be positively correlated $(\rho=0.165, p=0.01$ ). Academic qualification of teachers and different teaching level were associated with level of knowledge $(p=0.023, p=$ 0.021 ). Significant difference on knowledge score was found among teachers having different academic qualification $(p=0.019)$.

\section{Conclusion}

All teachers were aware about epilepsy, but their knowledge about epilepsy was not sufficient therefore, health education training program about epilepsy is needed for teachers.

\section{KEY WORDS}

Epilepsy, knowledge, school teachers 


\section{INTRODUCTION}

Epilepsy, a non-communicable disorder of human brain, affects people of all ages, race and social class. It is estimated that approximately 50 million people worldwide have epilepsy and nearly $80 \%$ of the people with epilepsy live in low and middle income countries and about three fourths of people with epilepsy living in low and middle income countries do not get the treatment they need. ${ }^{1-3}$ Epilepsy is an important public health problem which has influence on the emotional behavior, ability to work, family stability and self-esteem of the people and the social discrimination against person with epilepsy may be more devastating than the condition itself. ${ }^{4,5}$

According to a community based house hold survey carried out in Morang district covering 4,636 people epilepsy prevalence was found to be 7.3 per 1,000 population. ${ }^{6}$ At global forum, it is estimated that approximately $0.5 \%$ of school age children are affected by Epilepsy. ${ }^{7}$ During school years, a child's social, psychological, and physical development are shaped and this has significant impact on child's quality of life and future adult roles. ${ }^{8,9}$ Risks of educational underachievement, learning difficulties, social isolation, mental health problems and poor self-esteem are due to many social, economic and health problem and among them one is epilepsy. ${ }^{10,11}$

Teachers' knowledge on epilepsy have significant impact on managing psycho-social and physical difficulties including student's performance, social skill development, and future employment. ${ }^{12}$ Several studies suggest that teachers often have insufficient knowledge about epilepsy often misguiding them to form several baseless opinion in regards. ${ }^{12-19}$ So objectives of this study were to assess school teachers' knowledge about epilepsy in terms of good knowledge and poor knowledge and to identify its associated factors.

\section{METHODS}

A descriptive cross sectional study was conducted from $10^{\text {th }}$ June to $4^{\text {th }}$ July, 2014 among 165 school teachers of Kathmandu Metropolitan City. An ethical clearance from IRC-KUSMS was obtained prior to the study. Schools selected for the study were public as well as private English medium schools. Primary, lower secondary and secondary level school teachers were included in this study. Primary and lower secondary level teachers were placed under the category of primary teacher because most of them teach both on primary as well as on lower secondary level.

Purposes and objectives of the study were explained in detailed to all the respective principals and teachers of schools and a written informed consent was taken from each school as well as verbal consent was taken from all teachers who participated in the study. Identity of the participant teachers was kept confidential to ensure privacy and for encouraging accurate responses for questions.
Teachers who were not willing to take part in this study were excluded.

A self-administrated questionnaire consisting of structured and multiple choice questions were designed to collect information on the teacher's socio-demographic profile and knowledge about epilepsy. Twenty questions were included in this questionnaire to assess level of knowledge regarding epilepsy, covering: meaning, cause, risk factors, triggering factors, sign and symptoms, first aid management, treatment, management and prevention of epilepsy. A scoring system was developed for each component: each correct answer was given a score of one, a score of 0 for wrong answers and for multiple choice question answers a score of one was given for each correct answer. ${ }^{20}$ Total score was computed by adding all the individual scores, and score in terms of percentage were calculated. Questionnaire was pretested among $10 \%$ of the total sample and those participants included in pretest were excluded from the main study.

Participants were asked to fill up questionnaires and those were collected and checked for completeness and accuracy. Data were entered on MS Excel and SPSS version 20 was used for statistical analysis. Total score was calculated by adding individual scores and categorized in two categories: Good Knowledge and Poor Knowledge. "Good knowledge is defined as when respondents scored $\geq 50 \%$ when answering questions related to knowledge on epilepsy and poor knowledge as when respondents scored $<50 \%$." 21

After checking normality of scores, Mann-Whitney $U$ test and Kruskal Wallis test were used for checking significant difference on median knowledge score among different groups, chi-square test was used for testing association between knowledge categories and different background socio-demographic characteristic, Spearmen rank correlation analysis was used for modeling knowledge score and different variables. Binomial proportion test was carried out to test significant difference between/ among proportions. Level of significance was taken as 0.05 throughout the study and p-value less than 0.05 was taken as statistical significance

\section{RESULTS}

One hundred and sixty five school teachers working in six different schools were included during the study period. Out of them, majority were female ( $n=96,58.2 \%$ ). The age of those 165 teachers ranged between 20 and 57 years (Median $=29$ years) and their years of teaching experience ranged from six months to 25 years (Median $=6$ years). Most of the teachers belonged to the age group 20-29 years. Most of the teachers teaching experience was 0-10 years. Most teachers ( $n=75,45.5 \%)$ had a Bachelor's degree and majority $(n=89,53.9 \%)$ were primary school teachers. Eighty percent of the teacher did not have epileptic children in their school. Details demographic characteristic are presented on table 1. 
Table 1. Socio demographic and epilepsy related variables

$\mathrm{N}=165$

\begin{tabular}{|c|c|c|}
\hline Variable & Category & $n(\%)$ \\
\hline \multirow{2}{*}{ Sex } & Male & $69(41.8)$ \\
\hline & Female & $96(58.2)$ \\
\hline \multirow{4}{*}{ Education Level } & SLC & $04(2.4)$ \\
\hline & Intermediate & $38(23.0)$ \\
\hline & Bachelors & $75(45.5)$ \\
\hline & Masters & 48(29.1) \\
\hline \multirow{2}{*}{ Teaching Level } & Primary & $89(53.9)$ \\
\hline & Secondary & $76(46.1)$ \\
\hline \multirow{4}{*}{ Age } & $20-29$ & $85(51.5)$ \\
\hline & $30-39$ & $46(27.9)$ \\
\hline & $40-49$ & $28(17.0)$ \\
\hline & $50-59$ & $06(03.6)$ \\
\hline \multirow{3}{*}{$\begin{array}{l}\text { Total years of teach- } \\
\text { ing experiences }\end{array}$} & $0-10$ & $120(72.7)$ \\
\hline & $11-20$ & $038(23.0)$ \\
\hline & $21-30$ & $007(04.2)$ \\
\hline \multirow{8}{*}{$\begin{array}{l}\text { Source of Information } \\
\text { about Epilepsy* }\end{array}$} & Independent Study & $69(41.8)$ \\
\hline & Health personnel & 18(10.9) \\
\hline & Parents of students with epilepsy & $24(14.5)$ \\
\hline & Friends & $55(33.3)$ \\
\hline & TV & $66(40.0)$ \\
\hline & Radio & $40(24.2)$ \\
\hline & Internet & 29(17.6) \\
\hline & Newspaper & $50(30.3)$ \\
\hline \multirow{2}{*}{$\begin{array}{l}\text { Total Knowledge } \\
\text { Score }\end{array}$} & Poor (<50\%) & $79(47.9)$ \\
\hline & Good ( $\geq 50 \%)$ & $86(52.1)$ \\
\hline \multirow{2}{*}{$\begin{array}{l}\text { Epileptic children in } \\
\text { school }\end{array}$} & Yes & $33(20)$ \\
\hline & No & $132(80)$ \\
\hline
\end{tabular}

Distribution of knowledge score among teachers were found to be positively skewed with minimum score $33.33 \%$, maximum score $80.95 \%$ and median score $50.79 \%$. Mode knowledge score was found to be $52.38 \%$. Distribution of knowledge score are represented on figure 1 and figure 2

Proportion of good knowledge to poor knowledge for male teacher is 35: 34 and for female teacher is 51:45 and these proportion does not differs significantly $(p=0.999$ and $p=0.610$ ). Proportion of good knowledge to poor knowledge for primary school teacher is 39:50 and for secondary level teacher is 47:29, previous proportion does not differ significantly $(p=0.289)$ whereas later one is on boarder line $(p=0.05)$. Proportion of good knowledge to poor knowledge for teacher having higher secondary level academic qualification is $15: 27$, having bachelors level academic qualification is $40: 35$ and with masters level qualification is $31: 17$, but all these proportions does not differ significantly ( $p=0.088, p=0.644, p=0.059$ ) On aggregate proportion of teacher having good knowledge was not significantly high $(p=0.641)$ compared to proportion of teacher having poor

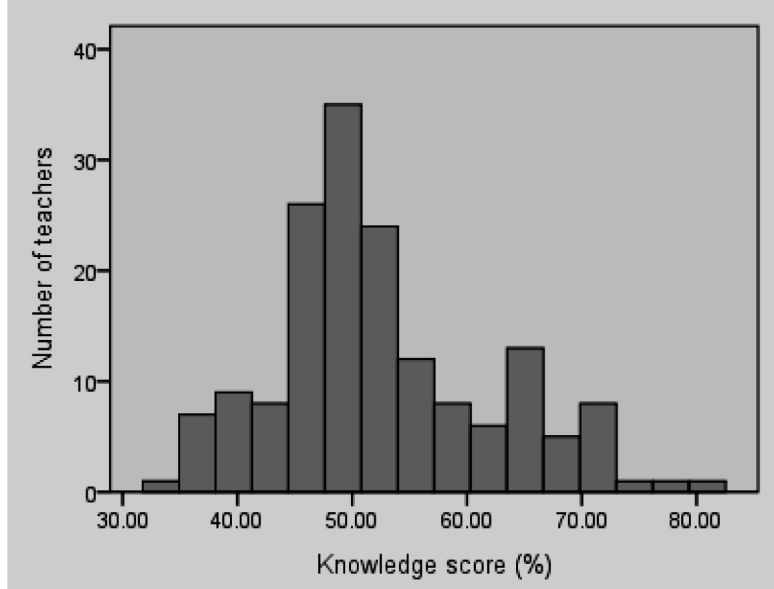

Figure 1. Distribution of Knowledge score among teachers

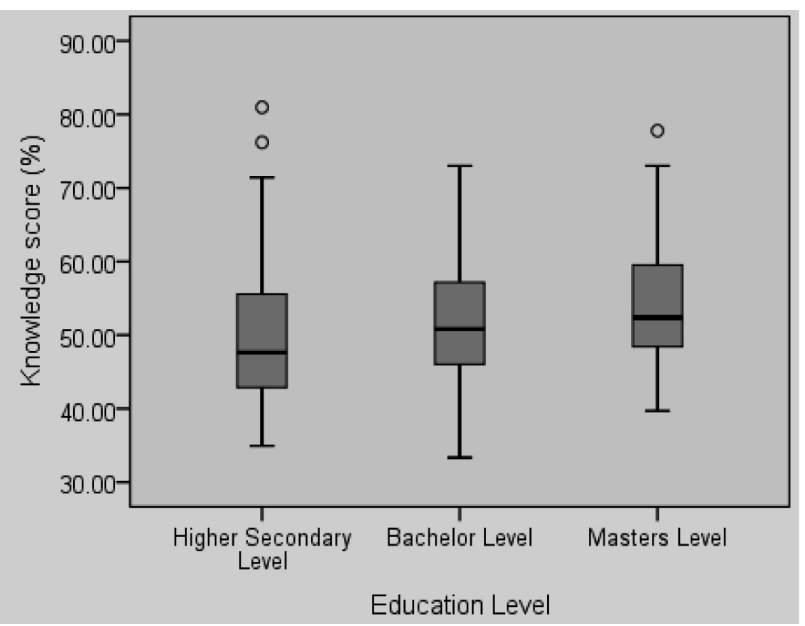

Figure 2. Distribution of knowledge score according to Academic Qualification of teachers

knowledge (86:79). Details about knowledge regarding epilepsy are shown in table 2.

Teacher's age did not correlate significantly with their knowledge about epilepsy. Significant positive correlation was found between total years of teaching experience and knowledge about epilepsy and was high in case of primary level teachers $(\rho=0.222)$ but in case of secondary level teachers it was low $(\rho=0.044)$ and was not significant. Among all the teachers teaching in primary and secondary level, years of teaching experiences and knowledge about epilepsy was found to be significantly positively correlated ( $\rho=0.165, p=0.01$ ). Education level of teacher and teaching level were found to be associated with level of knowledge $(p=0.023, p=0.021)$. Significant difference on knowledge score was found among teachers having different academic qualifications ( $p=0.019)$, however no significant difference was found on knowledge level according to sex, teaching level, age group and years of teaching experiences. Details are shown in table 3.

\section{DISCUSSION}

In a developing society like Nepal, teachers have an influencing role on society. They have a key role as educators 
Table 2. Knowledge of teachers about epilepsy

\begin{tabular}{|c|c|c|}
\hline \multicolumn{3}{|l|}{ Risk Factors of epilepsy* } \\
\hline & $\mathbf{N}$ & $\%$ \\
\hline Low oxygen during birth & 58 & 35.2 \\
\hline Lack of oxygen in brain due to blockage in blood vessels & 107 & 64.8 \\
\hline Abnormal level of sodium & 29 & 17.6 \\
\hline Low level of blood sugar & 33 & 20.0 \\
\hline \multicolumn{3}{|l|}{ Triggering factors of epilepsy* } \\
\hline Missing medication doses & 66 & 40.0 \\
\hline Heavy alcohol use & 47 & 28.5 \\
\hline Lack of sleep & 51 & 30.9 \\
\hline Flashing light & 22 & 13.3 \\
\hline Cocaine or other drug use & 48 & 29.1 \\
\hline \multicolumn{3}{|l|}{ Warning signs of epilepsy* } \\
\hline Headache & 26 & 15.8 \\
\hline Faint & 135 & 81.8 \\
\hline \multicolumn{3}{|l|}{ General sign and symptoms of epilepsy* } \\
\hline Loss of consciousness & 136 & 82.4 \\
\hline Foaming from mouth & 112 & 67.9 \\
\hline Yell or tonic cry & 29 & 17.6 \\
\hline Tongue bite & 71 & 43.0 \\
\hline \multicolumn{3}{|l|}{ Motor signs of epilepsy* } \\
\hline Alternating contraction and relaxation of muscle groups & 83 & 50.3 \\
\hline Eye movements & 21 & 12.7 \\
\hline Turning head to one side & 74 & 44.8 \\
\hline Speech arrest & 110 & 66.7 \\
\hline \multicolumn{3}{|l|}{ Sensory signs of epilepsy* } \\
\hline Seeing flashing lights or colors & 103 & 62.4 \\
\hline Hearing humming, buzzing noises & 63 & 38.2 \\
\hline
\end{tabular}

\begin{tabular}{|lll|}
\hline Unpleasant smelling & 24 & 14.5 \\
\hline Light headedness & 137 & 83.0 \\
\hline Autonomic signs of epilepsy* & & \\
\hline Increase heart rate & 102 & 61.8 \\
\hline Sweating & 105 & 63.6 \\
\hline Flushing & 75 & 45.5 \\
\hline Psychic symptoms of epilepsy* & & \\
\hline Experience of thinking that new situation had occurred & 31 & 18.8 \\
\hline before & & \\
\hline Fear & 103 & 62.4 \\
\hline Depression & 64 & 38.8 \\
\hline Anger & - & - \\
\hline First aid management of epileptic attack* & & \\
\hline Prevent crowds gathering around & 161 & 97.6 \\
\hline Protect the child from injury and position safely & 156 & 94.5 \\
\hline Restrain the movement & 34 & 20.6 \\
\hline Turn the child's head on one side & 59 & 35.8 \\
\hline Loosen all the tight clothing & 165 & 100 \\
\hline Do not put a spoon between teeth & 81 & 49.1 \\
\hline Do not give water to drink during attack & 84 & 50.9 \\
\hline Stay with the child until s/he is fully alert and oriented & 163 & 98.8 \\
\hline Child should be given rest or sleep after an epileptic attack & 164 & 99.4 \\
\hline Prevention of possible triggers in epilepsy* & & \\
\hline Avoiding flashing light & 59 & 35.8 \\
\hline Taking the medicine regularly & 113 & 68.5 \\
\hline Adequate sleep & 66 & 40.0 \\
\hline Avoiding alcohol & 66 & 40.0 \\
\hline Avoiding drugs & 84 & 50.9 \\
\hline * Multiple responses & & \\
\hline
\end{tabular}

Table 3. Association and significant difference between variables under study and level of knowledge

\begin{tabular}{|c|c|c|c|c|c|c|c|}
\hline \multirow[t]{2}{*}{ Category } & \multirow[t]{2}{*}{ Category } & \multicolumn{2}{|c|}{$\begin{array}{c}\text { Level of Knowledge } \\
n(\%)\end{array}$} & \multirow[t]{2}{*}{$\begin{array}{l}\text { P-value }{ }^{+} \\
\text {(Association) }\end{array}$} & \multirow[t]{2}{*}{$\begin{array}{l}\text { Range (\%) (Minimum } \\
\text { score -Maximum Score) }\end{array}$} & \multirow{2}{*}{$\begin{array}{l}\text { Median } \\
\text { Knowledge } \\
\text { Score (\%) }\end{array}$} & \multirow{2}{*}{$\begin{array}{l}\text { P-value } \\
\text { (significant dif- } \\
\text { ference) }\end{array}$} \\
\hline & & Poor & Good & & & & \\
\hline \multirow[t]{2}{*}{ Sex } & Male & $34(49.3)$ & $51(53.1)$ & \multirow[t]{2}{*}{0.761} & $33.33-77.78$ & 50.79 & \multirow[t]{2}{*}{$0.862^{++}$} \\
\hline & Female & $45(46.9)$ & $35(50.7$ & & $36.51-80.95$ & 50.79 & \\
\hline \multirow[t]{3}{*}{ Education Level } & Intermediate & $27(64.3)$ & $15(35.7)$ & \multirow[t]{3}{*}{$0.023 *$} & $34.92-80.95$ & 47.61 & \multirow[t]{3}{*}{$0.019^{*+++}$} \\
\hline & Bachelors & $35(46.7)$ & $40(53.3)$ & & 33.33-73.02 & 50.79 & \\
\hline & Masters & $17(35.4)$ & $31(64.6)$ & & $39.68-77.78$ & 52.38 & \\
\hline \multirow[t]{2}{*}{ Teaching Level } & Primary & $50(56.2)$ & $39(43.8)$ & \multirow[t]{2}{*}{$0.021^{*}$} & $34.92-80.95$ & 49.20 & \multirow[t]{2}{*}{$0.082^{++}$} \\
\hline & Secondary & $29(38.2)$ & $47(61.8)$ & & 33.33-77.78 & 52.38 & \\
\hline \multirow[t]{4}{*}{ Age } & $20-29$ & $42(49.4)$ & $43(50.6)$ & \multirow[t]{4}{*}{0.894} & $34.92-77.78$ & 50.79 & \multirow[t]{4}{*}{$0.555^{+++}$} \\
\hline & $30-39$ & $22(47.8)$ & $24(52.2)$ & & $39.68-80.95$ & 50.79 & \\
\hline & $40-49$ & $13(46.4)$ & $15(53.6)$ & & 33.33-73.02 & 50.79 & \\
\hline & $50-59$ & $02(33.3)$ & $04(66.7)$ & & $42.86-69.84$ & 56.34 & \\
\hline \multirow{3}{*}{$\begin{array}{l}\text { Total years of teaching } \\
\text { experiences }\end{array}$} & $0-10$ & $58(48.3)$ & $62(51.7)$ & \multirow[t]{3}{*}{0.570} & $34.92-77.78$ & 50.79 & \multirow[t]{3}{*}{$0.256^{+++}$} \\
\hline & $11-20$ & 19(50.0) & $19(50.0)$ & & $33.33-80.95$ & 50.00 & \\
\hline & $21-30$ & $02(28.6)$ & $05(71.4)$ & & $42.86-69.84$ & 58.73 & \\
\hline
\end{tabular}

*Significant

+ Chi-Square test for association

++ Mann-Whitney U test

+++ Kruskal Wallis Test 
and advisors in society. People of society seek advice on education, politics, as well as health from teachers. Teacher's knowledge about various aspects of epilepsy and its management, directly and indirectly reflects the awareness pattern of the population of society. Although this study covers only selected school of Kathmandu district but it reflects public health knowledge regarding epilepsy of our teachers' community.

The awareness on hearsay basis about epilepsy is shown to be high in several studies from developing as well as developed countries. ${ }^{22-28}$ Our study shows that the awareness of epilepsy among school teacher was very high $(100 \%)$ which was higher than the study carried out by Thacker et al. in India where only $97 \%$ of school teachers were aware among 568 teachers surveyed. ${ }^{14}$ In contrast, the awareness about epilepsy among school teacher in Thailand was found to be $57.8 \% .14$ Source of information about the disease in our study was mainly from Independent study and friends where as in India, it was from public media and from parents of students with epilepsy. ${ }^{29}$ These findings focus on two distinct dimensions about public health education in context of Nepalese society. First, more doctors have to be included on every public health awareness program, second the role of public media in spreading health awareness must be high. We should be very careful that most of the awareness about diseases with social stigma in Nepal is spread on large number by unqualified personnel and they even provide non-scientific therapeutic modalities to enhance their business.

Majority of school teachers in our study (69.7\%) felt epilepsy as a neurological disorder followed by mental disease (17.6\%). School teachers in India and Thailand gave reasonable answers to the questions about the cause of epilepsy, such as genetic (17.5\%), meningitis (11.2\%), encephalitis (13.3\%), neurocysticerosis $(6.5 \%)$, brain tumor (5.4\%), congenital malformation (4.7\%), head injury (20.9\%) and unknown cause (20.4\%). ${ }^{29}$

Very few (15.2\%) said that after an epileptic attack person cannot remember about the event. Once warning signs are seen, $45.5 \%$ said that child should be kept safe from harmful objects and $26.1 \%$ said they should be given medicine. Almost half of the respondents (53.9\%) believed that identification tag, batch or bracelet to students with epilepsy was a good idea.

According to our study, $4.2 \%$ of teacher believed that epilepsy is due to super natural power. In countries like India, china, Thailand and Taiwan there is also such belief among teachers. ${ }^{26,30-32}$ Belief on super natural power is due to the fact that peoples' faith and belief are deep rooted and shaped by cultural and religious practices. This ratio of supernatural aspect as the cause of epilepsy is higher in developing countries compared to developed ones.

Percentage of teachers who felt epilepsy as a curable disease is higher, as shown by our study (95.8\%) than that of India (62\%) and other countries like Thailand, Chinese, Korean, Italy and Brazilian teachers. ${ }^{14,29-31}$ Majority of the teachers $(95.8 \%)$ believe that epilepsy can be cured by getting treatment with health personal, whereas this percentage is high than the study carried out in South India (77.7\%). ${ }^{14,25}$ In our study, academic qualification of teacher and teaching level in school are associated with level of knowledge about epilepsy, but years of teaching experiences, age of teacher and gender are not associated with knowledge about epilepsy. Teacher's age did not correlate significantly with their knowledge about epilepsy but years of teaching experiences and knowledge about epilepsy was found to be significantly positively correlated. According to the similar study carried out among school teachers in Iran, knowledge was associated with academic qualifications and years of teaching experience of teachers. ${ }^{32}$ Similarly, another studies carried out by Reyace et al. on 20 school teachers of Iran, there was no significant association between teachers' knowledge and their gender, age and education level. ${ }^{33}$ Similarly, no meaningful relationship was found between the teacher's knowledge and gender according to the study carried out by Ghaydaa et al. on Egypt. ${ }^{34}$

Similarly, in a study carried on Saudi Arabia, teacher's age, gender and years of teaching experience did not correlate significantly with their knowledge about epilepsy. However, teachers with higher education (college or university degrees) were more likely to have good knowledge when compared to those with less education. ${ }^{35}$ Some other studies suggest that there is no any correlations between teacher's age, gender and years of teaching experience with their knowledge about epilepsy. ${ }^{35}$ According to the study carried out in US among 512 teachers, knowledge of epilepsy was not related to gender and education level, but was positively correlated with teachers age and years of teaching experiences. ${ }^{36}$ Other studies have found the association of knowledge about epilepsy with more years of teaching experience and female gender. ${ }^{36-38}$

In our study numbers of primary school teachers were 89 and out of them 56.2\% have poor knowledge about epilepsy which was higher than the study carried out in 118 primary school teachers in Port Harcourt, Nigeria where only $43 \%$ have poor knowledge. ${ }^{39}$ Similarly number of secondary level teacher were 76 and out of them $38.2 \%$ have poor knowledge, whereas on similar study carried out among 269 school teachers randomly selected from various secondary schools in Osogbo, the Osun State capital in South-West Nigeria, about $70 \%$ of the teachers reported their general knowledge of epilepsy is lower than half of total score. ${ }^{40} \mathrm{~A}$ survey conducted among one hundred teachers of nine public schools of Brazil, $20 \%$ accepted that they had a poor knowledge regarding epilepsy, ${ }^{41}$ where as in our study it is very high (47.9\%). Large number of poor knowledge regarding epilepsy in Nepal is due to less public health awareness program with focus on epilepsy and least 
number of teachers training program on Health Education.

There were some limitations of our study. Our sample does not represent all teachers working in Kathmandu Metropolitan City. This will limit our ability to generalize our findings throughout the city. However, our sample included schools with representation of all ages, experiences, and both male and female teachers, so findings of this research might be a reference on this area for other researchers. Another limitation of this study is to generalize our finding to all categories of teachers as we did not include teachers teaching on higher secondary level and above.

\section{CONCLUSION}

All teachers were aware about epilepsy, but their knowledge about epilepsy was not sufficient and no significant majority of teachers had good knowledge, therefore, health education training program about epilepsy is needed for teachers.

\section{REFERENCES}

1. World Health Organization, Oral health [Internet]; [cited $25^{\text {th }}$ July 2015]. Available from: http://www.who.int/mediacentre/factsheets/ fs999/en/

2. Meinardi H, Scott RA, Reis R, Sander JW. The treatment gap in epilepsy: the current situation and ways forward. Epilepsia. 2001; 42: 136-49.

3. Ngugi, Anthony K., Christian Bottomley, Immo Kleinschmidt, Josemir W. Sander, and Charles R. Newton. "Estimation of the burden of active and life-time epilepsy: A meta-analytic approach." Epilepsia 2010; 51: 883-890.

4. Rwiza H T, Kilonzo GP, Haule J, Matuja WBP, Mteza I et al. Prevalence and incidence of epilepsy in Ulanga, a rural Tanzanian district: a community-based study. Epilepsia. 1992; 33 : 1051-1056.

5. Millogo A, and Siranyan AS. Knowledge of epilepsy and attitudes towards the condition among schoolteachers in Bobo-Dioulasso (Burkina Faso). Epileptic disorders. 2004; 6: 21-26.

6. Nepal MK, Sharma VD, Shrestha PM. Epilepsy prevalence, a case study of Morang District. International workshop on epilepsy conducted jointly by EPICADEC epilepsy care developing countries and Dept. of Psychiatry, IOM Institute of medicine. April 15, 1996, Kathmandu, Nepal, 17-23.

7. Leppick IE. Contemporary diagnosis and management of the patient with epilepsy. ( $5^{\text {th }}$ ed.) 2001; Newtown, PA: Handbooks in Health Care.

8. Williams J. Learning and behavior in children with epilepsy. Epilepsy Behave. 2003; 4:107-11.

9. Kokkonen J, Kokkonen E, Saukkonen A, Pennanen P. Psychosocial outcome of young adults with epilepsy in childhood. I Neurol Neurosurg Psychiatry. 1997;62:265-8.

10. Sbarra DA, Rimm-Kaufmann SE, Pianta RC. The behavioral and emotional correlates of epilepsy in adolescence: a seven-year followup study. Epilepsy Behav. 2002;2:358-67.
Such programs would increase broad knowledge of epilepsy among teachers which will consequently improve quality of life of epileptic child from the very beginning of life. This must be addressed in time for enhancing better quality of life of people living with epilepsy. We selected primary, lower secondary and secondary level teachers due to the importance of these early stages in the school career of children with epilepsy and their psychosocial development. It will be good to evaluate teacher's knowledge on national level.

\section{ACKNOWLEDGEMENT}

We would like to express our sincere gratefulness to all the school management team and participating teachers in this study.

Similarly, our thankfulness also goes to Advocate Chandra Prasad Luitel for editing and looking into the rhetoric of this article.

11. Fraser RT, Clemmons DC. Vocational and psychosocial interventions for youths with seizure disorders. Childhood epilepsies: neuropsychological, psychosocial, and intervention aspects. 1989; 201-18.

12. Hsieh L, Chiou H. Comparison of epilepsy and asthma perception among preschool teachers in Taiwan. Epilepsia. 2001; 42:647-50.

13. Kankirawatana P. Epilepsy awareness among school teachers in Thailand. Epilepsia. 1999; 40:497-501.

14. Bannon MJ, Wildig C, Jones PW. Teachers' perceptions of epilepsy. Arch Dis Child. 1992;67:1467-71.

15. Mielke J, Adamolekun B, Ball D, Mundanda T. Knowledge and attitudes of teachers towards epilepsy in Zimbabwe. Acta Neurol Scand. 1997;96: 133-7.

16. Dantas FG, Cariri GA, Ribeiro Filho AR. Knowledge and attitudes toward epilepsy among primary, secondary and tertiary level teachers. Arq Neuro-Psiquiatr. 2001;59:712-6.

17. Madsen LP. Danish primary school teachers' knowledge about epilepsy in children. Ugeskrift Laeger. 1996;158:1977-80.

18. Prpic I, Korotaj Z, Vlasic-Cicvcaric I, Paucic-Kirincic E, Valerjev A, Tomac V. Teachers opinions about capabilities and behavior of children with epilepsy. Epilepsy Behav. 2003;4:142-5.

19. Seva-Diaz A, Abad Alegria F, Ferrando L. Epileptics at school. Arch Neurobiol. 1986;49:113-20.

20. Afrose L, Banu B, Ahmed K R, Khanom K Factors associated with knowledge about breastfeeding among female garment workers in Dhaka city. WHO South-East Asia Journal of Public Health. 2012;1: 249-55.

21. Teferi J. assessment of knowledge, attitude, and practice related to epilepsy: a community-based study. Neuropsychiatric Disease and Treatment. 2015;11: 1239-46. 
22. Mclin WM, deBoer HM. Public perceptions about epilepsy. Epilepsia. 1995;36:957-9.

23. Jensen R, Dam Me. Public attitudes toward epilepsy in Denmark. Epilepsia. 1992;33:459-63.

24. Radhakrishnan K, Pandian JD, Santhoshkumar T, Thomas SV, Deetha TD, Sarma PS et al. Prevalence, knowledge, attitude, and practice of epilepsy in Kerala, South India. Epilepsia. 2000; 41: 1027-35.

25. Thien DD, Pieree J. Survey of public awareness, attitudes, and understanding toward epilepsy in Nhan Chinh, Hanoi, Vietnam, in 2003. Epilepsy \& Behavior. 2003;8:176-80.

26. Chung MY, Chang YC, Las YH, Lai CW. Survey of public awareness, understanding and attitudes toward epilepsy in Taiwan. Epilepsia. 1995;36:488-93.

27. Choi SK, Park KA, Lee HJ, Park MS, Lee CH, Cheon SE et al. Familiarity with knowledge of and attitude toward epilepsy in residents of Seoul, South Korea. Acta Neurol Scand. 2004;110:39-45.

28. Rwiza HT, Matumja WBP, Kilonzo GP, Hawe J, Mbera P, Mwangombola $\mathrm{R}$, et al. Knowledge attitude and practice towards epilepsy among rural Tanzanian residents. Epilepsia. 1993;34:1017-23.

29. Thacker AK, Verma A M Ji R, Thacker P, Mishra P. Knowledge awareness and attitude about epilepsy among schoolteachers in India. Seizure. 2008;17;684-690.

30. Lai CW, Hwang XS, Lai YH, Zhang ZQ, Lie GJ, Yang ME. Survey of public awareness, understanding and attitudes towards epilepsy in Henan Province, China. Epilepsia. 1990;31: 182-7.

31. Kim MK, Kim IK, Kim BC, Cho KH, Kim SJ, Moon JD. Positive trends of public attitudes toward epilepsy after public education campaign among rural Korean residents. J Korean Med Sci. 2003;18:248-54.

32. Karimi N, Heidari M. Knowledge and attitudes toward epilepsy among school teachers in West of Iran. Iranian Journal of Neurology. 2015;14:130-5.
33. Reyace H, Kaheni S, Sharifzadeh G. Teachers' knowledge about epilepsy. Journal of Nursing and Midwifery Sciences. 2014;1: 27-32.

34. Ghaydaa A, Shehata A, Dalia G. Mahranb. Knowledge, Attitude and Practice Regarding Epilepsy among School Teachers in Assiut city, Egypt. Epilepsy Res. 2010; 92:191-200.

35. Abulhamail AS, Al-Sulami FE, Alnouri MA, Mahrous NM, Joharji DG, Albogami MM et al. Primary school teacher's knowledge and attitudes toward children with epilepsy. Seizure. 2014;23:280-3.

36. Bishop M, Boag EM. Teachers' knowledge about epilepsy and attitudes toward students with epilepsy: results of a national survey. Epilepsy \& Behavior. 2006;8:397-405.

37. Bishop M, Slevin B. Teachers' attitudes toward students with epilepsy: results of a survey of elementary and middle school teachers. Epilepsy Behav. 2004;5:308-15.

38. Antonak RF, Livneh H. Development, psychometric analysis, and validation of an error-choice test to measure attitudes toward persons with epilepsy. Rehab Psychol. 1995;40:25-39.

39. Alikor EA, Essien AA. Childhood epilepsy: knowledge and attitude of primary school teachers in Port Harcourt, Nigeria. Nigerian journal of medicine: journal of the National Association of Resident Doctors of Nigeria. 2004;14:299-303.

40. Mustapha AF, Odu OO, Akande O. Knowledge, attitudes and perceptions of epilepsy among secondary school teachers in Osogbo South-West Nigeria: a community based study. Nigerian journal of clinical practice. 2013;16:12-8.

41. Fernandes PT, Ana LA N, Ulisses A, Paula C, Ricardo P, Hanneke M et al. Teachers perception about epilepsy. Arquivos de Neuropsiquiatria.2007;65:28-34. 